\title{
$\mathrm{HVPE}$ 법에 의해 성장된 $\mathrm{AlN}$ 에피층의 $\mathrm{V} / \mathrm{III}$ 비에 따른 특성변화
}

\author{
손호기 $^{1,3} \cdot$ 임태영 $^{1} \cdot$ 이미재 $^{1} \cdot$ 김진호 $^{1} \cdot$ 김영희 $^{1} \cdot$ 황종희 $^{1 \dagger} \cdot$ 오해 곤 $^{2} \cdot$ 최영준 $^{2} \cdot$ 이혜용 $^{2} \cdot$ 김형순 $^{3}$ \\ 1한국세라믹기술원, ${ }^{2}$ 루미지엔테크, ${ }^{3}$ 인하대학교 신소재공학부
}

\section{Effect of V/III Ratio Variation on the Properties of AlN Epilayers in HVPE}

\author{
Hoki Son ${ }^{1,3}$, Tae-Young Lim ${ }^{1}$, Mijai Lee ${ }^{1}$, Jin-Ho Kim ${ }^{1}$, Younghee Kim ${ }^{1}$, Jonghee Hwang ${ }^{1 \dagger}$, \\ Hae-Kon $\mathrm{Oh}^{2}$, YoungJun, $\mathrm{Choi}^{2}$, Hae-Yong $\mathrm{Lee}^{2}$ and Hyung Sun $\mathrm{Kim}^{3}$ \\ ${ }^{1}$ Korea Institute of Ceramic Engineering \& Technology, 233-5, Gasandong, Geumchungu, Seoul, Korea \\ ${ }^{2}$ LumiGNtech Co., 233-5 Gasan-dong, Guemcheon-gu, Seoul 153-801, Korea \\ ${ }^{3}$ School of Materials Science and Engineering, Inha University, Incheon 402-751, Korea
}

(2013년 11월 6일 접수: 2013년 11월 29일 최종수정 : 2013년 12월 1일 채택)

\begin{abstract}
AIN epilayers were grown on a c-plane sapphire substrate using hydride vapor phase epitaxy (HVPE). A series of AIN epilayers were grown at $1120^{\circ} \mathrm{C}$ with $\mathrm{V} / \mathrm{III}$ ratios $1.5,2.5$ and 3.5 , and the influence of $\mathrm{V} / \mathrm{III}$ ratio on their properties was investigated. As the V/III ratio was increased, the surface roughness (RMS roughness), Raman shift of $\mathrm{E}_{2}$ high peaks and fullwidth at half-maximum (FWHM) of symmetrical (002) \& asymmetrical (102) of the AIN epilayers increased. However, the intensities of the Raman $\mathrm{E}_{2}$ high peaks were reduced. This indicates that the crystal quality of the grown AIN epilayers was degraded by activation of the parasitic reaction as the V/III ratio was increased. Smooth surface, stress free and high crystal quality AIN epilayers were obtained at the V/III ratio of 1.5. The crystal quality of AlNepilayers is worsened by the promotion of three-dimensional (3D) growth mode when the flow of $\mathrm{NH}_{3}$ is high.
\end{abstract}

Key words $\underline{\text { V/III ratio, }}$ AlN, HVPE, template.

\section{1. 서 론}

$\mathrm{AlN}$ (질화 알루미늄) 단결정은 $6.2 \mathrm{eV}$ 의 넓은 밴드갭 에 너지, 높은 열전도도 $\left(3.2 \mathrm{~W} \mathrm{~cm}^{-1} \mathrm{~K}^{-1}\right)$ 그리고 $\mathrm{GaN}$ 과 격 자상수 차이가 작기 때문에 $\mathrm{AlGaN}$ 기반의 $\mathrm{UV} \mathrm{LED}$, piezoelectric 센서, 고출력, 고온 작동 전자소자에 적합 하다. ${ }^{1)}$ 특히 $210 \mathrm{~nm}$ 이상의 단파장영역에서의 높은 투 영도 때문에 DUV-LED(deep ultraviolet light emitting diodes)와 레이저 다이오드(LD)에 적합한 기판 재료이다.2) $\mathrm{AlGaN}$ 기반의 고효율 DUV-LED를 구현하기 위해서는 낮은 threading dislocation 밀도를 갖는 AlN template 개발이 매우 중요하다. Epitaxial lateral overgrowth(ELO) 기법을 적용하여 균열 없는 $\mathrm{AlN}$ 에피층을 사파이어 기
판 위에 성장시킴으로 낮은 threading dislocation 밀도의 AIN template은 얻어질 수 있었다. ${ }^{2)}$ 그러나 두껍고 고품 질의 균열 없는 $\mathrm{AlN}$ 에피층의 성장은 $\mathrm{Al}$ 원자의 낮은 표면 이동도, 기판과 에피층의 격자상수와 열팽창계수의 차이, 높은 온도에서 강한 parasitic 반응 등으로 매우 어 렵다. ${ }^{3)} \mathrm{AlN}$ 에피층 성장을 위해서는 $\mathrm{MBE}$, MOVPE, HVPE 등 여러 가지 기술이 사용되는데 두꺼운 AIN 에 피층을 사파이어 기판 위에 성장시키기 위해서는 HVPE 공법이 주로 사용된다. HVPE에 의한 성장은 여러 가지 장점을 가진다. 예를 들어 높은 성장률, 넓은 면적에서 의 균일성, 낮은 불순물 함량 등이다. ${ }^{4)} \mathrm{HVPE}$ 공법으로 $\mathrm{AlCl}_{3}$ 와 $\mathrm{NH}_{3}$ 를 사용하여 사파이어 기판 위에 고품질의 $\mathrm{AlN}$ 에피층를 성장시키려면 고온이 필요하다. ${ }^{5)}$ 그러나 고

\footnotetext{
${ }^{\dagger}$ Corresponding author

E-Mail : jhhwang@kicet.re.kr (J. H. Hwang, KICET)
}

(C) Materials Research Society of Korea, All rights reserved.

This is an Open-Access article distributed under the terms of the Creative Commons Attribution Non-Commercial License (http://creativecommons.org/licenses/by-nc/3.0) which permits unrestricted non-commercial use, distribution, and reproduction in any medium, provided the original work is properly cited. 
온에서의 성장은 $\mathrm{AlN}$ 에피층과 사파이어 기판 사이에 큰 열팽창계수 차이로 성장 후 상온까지 냉각되는 동안 $\mathrm{AlN}$ 에피층과 사파이어 기판 양쪽에 크랙이 발생하는 단점 이 있다. ${ }^{5}$ 따라서 양질의 $\mathrm{AlN}$ 에피층을 성장시키기 위 해서는 최적의 성장조건 설정이 매우 중요하다. 본 연 구에서는 $\mathrm{V} / \mathrm{III}$ 족 비를 $1.5 \sim 3.5$ 까지 변화시킨 후 각 조 건에서 생성된 AIN layer의 특성을 살펴보았다.

\section{2. 실험 방법}

$\mathrm{AlN}$ 에피층은 국내 제작된 수평형 $\mathrm{HVPE}$ 성장로에서 성장시켰으며 Fig. 1에 본 연구에 사용된 HVPE 성장 로의 도식도를 보였다. 성장공정은 상압에서 진행되었으 며, 6개의 독립적으로 제어되는 히터로 온도를 조절하였 다. 공정영역은 소스영역(source zone)과 성장영역(growth zone)의 두 부분으로 구성되어있다. 활성가스(Active gas) 로는 암모니아 $\left(\mathrm{NH}_{3}\right)$ 와 염화수소 $(\mathrm{HCl})$ 를 사용하였고, 3족 원료로는 금속 $\mathrm{Al}$ 을 사용하였다. 기판으로는 2 인치 크기 의 (0001) 사파이어를 암모니아 $\left(\mathrm{NH}_{3}\right)$ 로 10 분간 질화 처 리한 후 사용하였다. 금속 $\mathrm{Al}$ 은 분리된 석영반응관 튜 브 내에 위치하고, 보트(boat)가 위치한 영역의 온도는 $550{ }^{\circ} \mathrm{C}$ 로 설정하였다. 여기서 금속 $\mathrm{Al}$ 과 $\mathrm{HCl}$ gas가 반 응하여 염화알루미늄 $\left(\mathrm{AlCl}_{3}\right)$ 가스를 형성한다. $\mathrm{Al}$ 소스영 역에서 지배적으로 일어나는 반응은 다음과 같다.

$$
\mathrm{Al}(\mathrm{s})+3 \mathrm{HCl} \rightarrow \mathrm{AlCl}_{3}(\mathrm{~g})+3 / 2 \mathrm{H}_{2}
$$

소스 영역의 온도는 $790{ }^{\circ} \mathrm{C}$ 아래서 진행되어야 한다. $790{ }^{\circ} \mathrm{C}$ 이상의 온도에서는 $\mathrm{Al}$ 이 염화수소와 반응하여 $\mathrm{AlCl}$ 이 생성되는데 이 $\mathrm{AlCl}$ 은 $\mathrm{HVPE}$ 장비의 석영관과 반응하여 기기를 손상시킨다. ${ }^{6}$ 생성된 $\mathrm{AlCl}_{3}$ 가스는 캐 리어 가스인 질소 $\left(\mathrm{N}_{2}\right)$ 에 의해 성장영역으로 이동된다. 사 파이어 기판의 표면처리와 $\mathrm{AlN}$ 성장은 성장영역에서 이 루어진다. 성장영역에 사파이어 기판을 장입한 후, $\mathrm{NH}_{3}$ 와 $\mathrm{N}_{2}$ 의 혼합 가스를 주입하여 표면처리를 실행한다. 표 면 처리 후에 $\mathrm{AlN}$ 을 성장시킨다. 성장영역에서의 반응은,

$$
\mathrm{AlCl}_{3}+\mathrm{NH}_{3} \rightarrow \mathrm{AlN}(\mathrm{s})+3 \mathrm{HCl}
$$

이다. 본 실험에서는 $\mathrm{V} / \mathrm{III}$ 족 비의 변화에 따른 $\mathrm{AlN}$

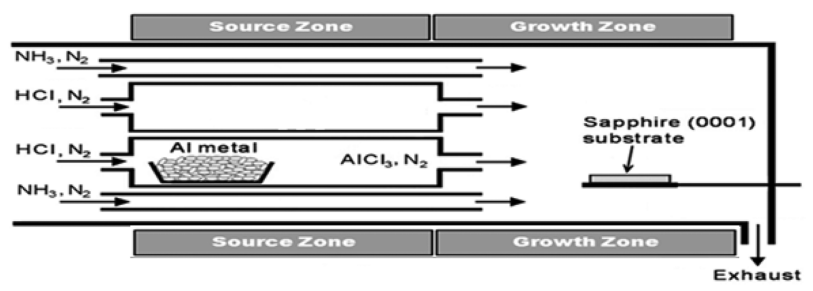

Fig. 1. Schematic diagram of the HVPE system used in this study.
에피층의 특성변화를 관찰하였다. OM과 AFM(JSPM5200, JEOL, Japan)을 통해 표면 거칠기(RMS roughness) 를 조사하였고, $\mathrm{HR}-\mathrm{XRD}$ 와 Raman 분석을 통해 결정성 을 조사하였다.

\section{3. 결과 및 고찰}

Table 1에는 AlN 에피층의 질화처리, 성장온도, Alflux, $\mathrm{NH}_{3}$ flux, V/III족 비 등의 성장 조건을 정리하여 나타내었다. Al-flux를 고정시키고, $\mathrm{NH} 3$ flux을 증가시켜 서 $\mathrm{V} / \mathrm{III}$ 족비를 $1.5,2.5,3.5$ 로 1.0 씩 증가 시켜가면서 $\mathrm{AlN}$ 에피층을 성장시켰다. 그리고 성장하기 전에 모든 사 파이어 기판을 $\mathrm{NH}_{3}$ 을 사용하여 10 분 동안 질화시켰다. 성 장온도는 소스 영역에서 $600{ }^{\circ} \mathrm{C}$, 성장 영역에서 $1120{ }^{\circ} \mathrm{C}$ 로 성장시키고, $\mathrm{AlN}$ 의 성장시간은 성장속도를 고려하여 동일한 두께성장을 하도록 각각 17 분, 20 분, 30 분으로 성 장시켰다. Fig. 2에는 광학현미경으로 관찰한 V/III족 비 에 따른 표면상태 변화를 나타내었다. 광학현미경으로 전 체적으로 표면을 관찰한 결과 모든 시료의 표면에서 크 랙은 발견되지 않았고 $\mathrm{V} / \mathrm{III}$ 족 비가 증가할수록 $\mathrm{AlN}$ 입 자크기가 작아지는 것을 확인할 수 있었다. V/III족 비 가 낮을 때에는 $\mathrm{NH}_{3}$ flux가 작아 상대적으로 $\mathrm{Al}$ 원자 의 확산 거리가 증가하여 $\mathrm{AlN}$ 입자크기가 2차원적(twodimensional)으로 잘 성장되어 $\mathrm{AlN}$ 입자의 크기가 증가 한 것으로 볼 수 있다. 한편 높은 $\mathrm{V} / \mathrm{III}$ 족 비 일 때는 상대적으로 높은 $\mathrm{NH}_{3}$ flux로 인해 $\mathrm{AlN}$ 합성반응이 활 성화되어, $\mathrm{Al}$ 원자의 확산 거리가 감소하여 2차원적으로 넓은 면적으로 성장을 하지 못했기 때문에 작은 알갱이 형태로 성장한 것으로 판단 된다. ${ }^{7)}$ Fig. 3에는 AFM으 로 관찰한 표면조도를 나타내었다. $\mathrm{AlN}$ 에피층 표면 RMS roughness 값은 시료 a $5.13 \mathrm{~nm}$, 시료 b $6.22 \mathrm{~nm}$, 시료 c $6.86 \mathrm{~nm}$ 로 $\mathrm{V} / \mathrm{III}$ 족 비가 증가할수록 표면조도가 나빠지는 것을 볼 수 있었다. Fig. 2의 광학현미경 사진 에서 확인된 바와 같이 $\mathrm{V} / \mathrm{III}$ 족 비가 증가하면서 $\mathrm{AIN}$ 입 자크기가 작아졌는데도 불구하고 RMS roughness 값이 증가하는 이유는 $\mathrm{V} / \mathrm{III}$ 족 비 증가 시 반응성의 질소 원 자 수 증가로 $\mathrm{Al}$ 이온이 기판에서 활성화되기 전에 기 상 합성반응이 활성화되어 2차원적 성장보다는 3 차원적

Table 1. Growth conditions of AIN epilayers.

\begin{tabular}{c|cc|ccc|c}
\hline \multirow{2}{*}{ Run No } & \multicolumn{2}{|c|}{ Nitridation } & \multicolumn{3}{|c|}{ Growth } & \multirow{2}{*}{$\begin{array}{c}\text { V/III } \\
\text { ratio }\end{array}$} \\
\cline { 2 - 6 } & $\mathrm{NH}_{3}$ & Time & $\mathrm{HCl}$ & $\mathrm{NH}_{3}$ & Time & \\
\cline { 2 - 6 } & $\mathrm{slm}$ & $\mathrm{min}$ & $\mathrm{slm}$ & $\mathrm{slm}$ & $\min$ & \\
\hline Sample a & 1.0 & 10 & 0.1 & 0.15 & 17 & 1.5 \\
Sample b & 1.0 & 10 & 0.1 & 0.25 & 20 & 2.5 \\
Sample c & 1.0 & 10 & 0.1 & 0.35 & 30 & 3.5 \\
\hline
\end{tabular}




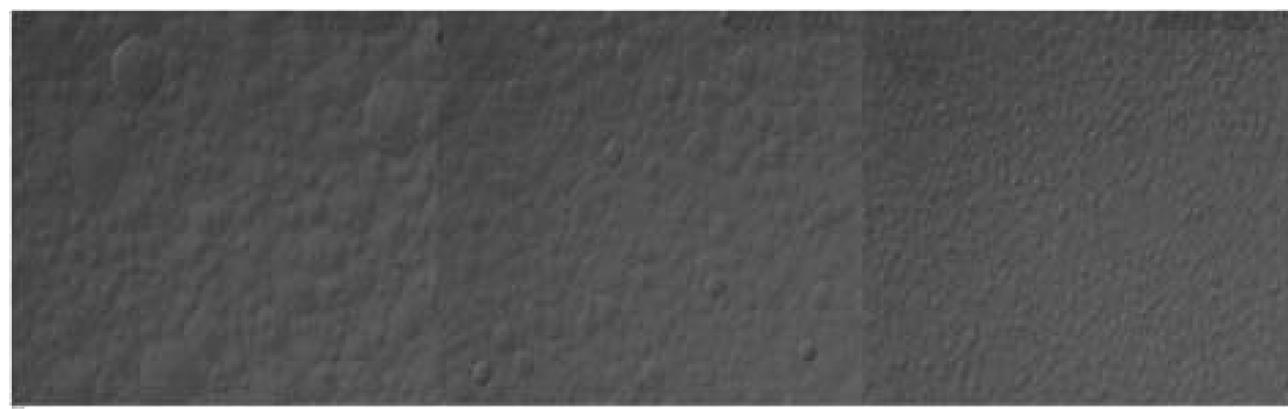

(a) 1.5

(b) 2.5

(c) 3.5 .

Fig. 2. OM images of the surface of AIN epilayers with different V/III ratios (a) 1.5 , (b) 2.5 and (c) 3.5 .

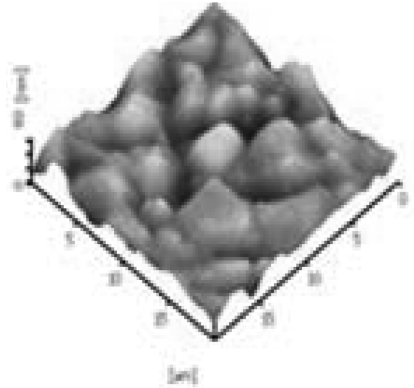

(a)

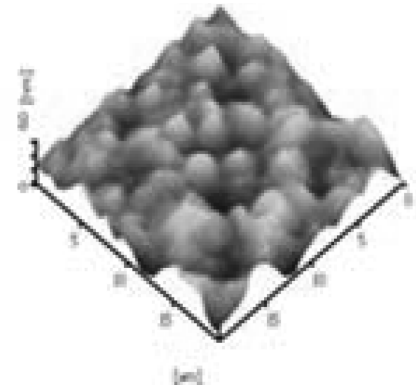

(b)

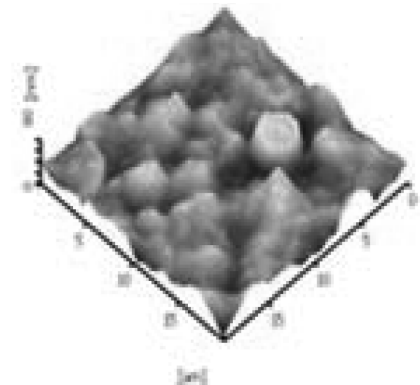

(c)

Fig. 3. $20 \mu \mathrm{m} \times 20 \mu \mathrm{m}$ AFM images of the surface of AlN epilayers with different V/III ratios (a)1.5, (b) 2.5 and (c) 3.5 .

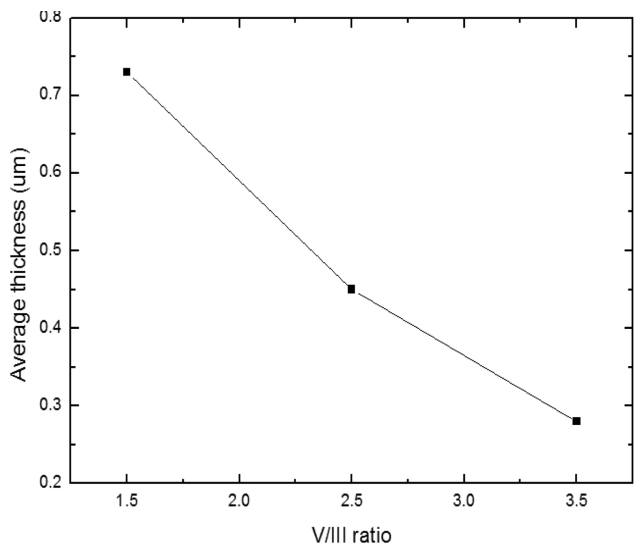

(a)

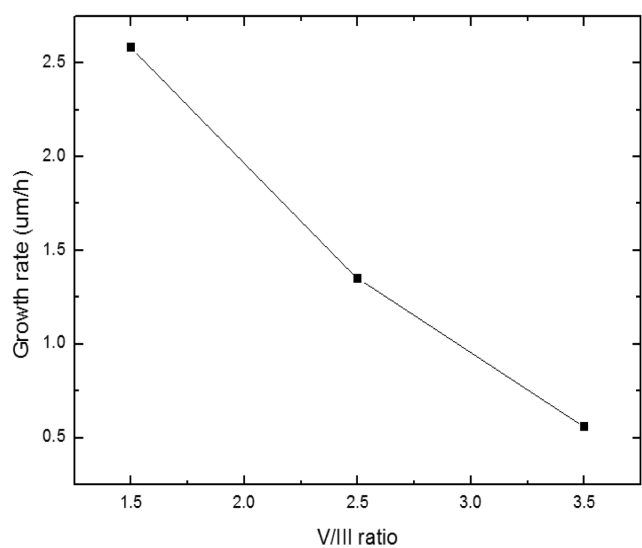

(b)

Fig. 4. Thickness and growth rate of AIN epilayers with the variation of the V/III ratio (a) thickness \& (b) growth rate.

(three-dimensional) 성장이 지배적으로 되어 표면조도가 나빠지는 것으로 판단된다. 상대적으로 낮은 $\mathrm{V} / \mathrm{III}$ 족 비 조건 하에서는 반응성의 질소 원자수가 적어 기상합성 보다는 기판 표면 위에서의 $\mathrm{Al}$ 이온의 이동이 활성화되 어 2차원 성장을 함으로 RMS roughness 값이 낮아져 서 표면조도가 낮아지는 것으로 판단된다. ${ }^{8,9)} \mathrm{Fig}$. 4(a)는 $\mathrm{V} / \mathrm{III}$ 족 비에 따른 $\mathrm{AlN}$ 에피층의 평균두께 변화를, Fig. 3 (b)는 $\mathrm{V} / \mathrm{III}$ 족 비에 따른 $\mathrm{AlN}$ 에피층의 성장률을 나타 내었다. $\mathrm{V} / \mathrm{III}$ 족 비가 $1.5,2.5,3.5$ 로 증가하면서 $\mathrm{AIN}$ 에 피층의 평균두께는 $0.73 \mu \mathrm{m}, 0.45 \mu \mathrm{m}, 0.28 \mu \mathrm{m}$ 로 감소하
였으며 이에 따라 성장률도 $2.58 \mu \mathrm{m} / \mathrm{h}, 1.35 \mu \mathrm{m} / \mathrm{h}, 0.56$ $\mu \mathrm{m} / \mathrm{h}$ 로 감소하였다. V/III족 비의 증가는 Fig. 2, 3의 표 면형상 및 표면조도 결과에서 확인된 바와 같이 반응성 의 질소 원자 수 증가로 기상 합성반응이 활성화되는 반 면 많은 반응성의 질소 원자 수 증가는 parasitic 반응 을 증가시켜 오히려 기판 위에서의 에피성장을 어렵게 만들기 때문에 성장률이 감소하는 것으로 판단된다. ${ }^{8,10)}$ Fig. 5에는 AlN 에피층의 (002) 대칭면과 (102) 비 대칭 면 X-ray rocking 곡선을 나타내었다. (002) 대칭면은 박 막의 c축 방향 변형을 측정할 수 있어 나선형 전위형성 


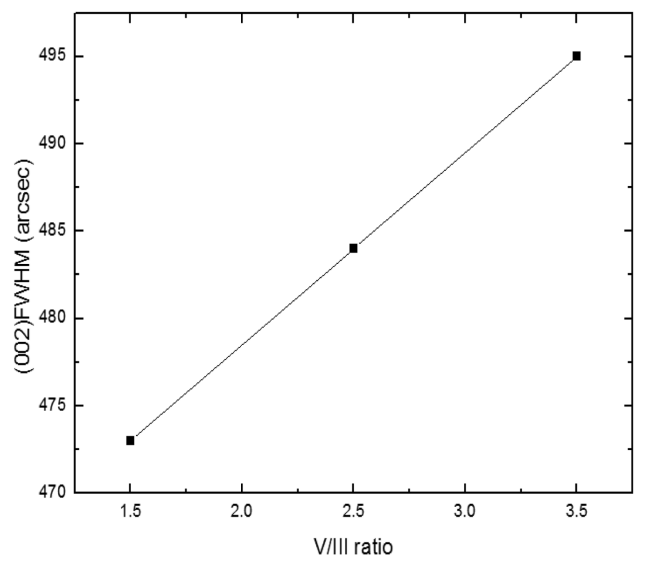

(a)

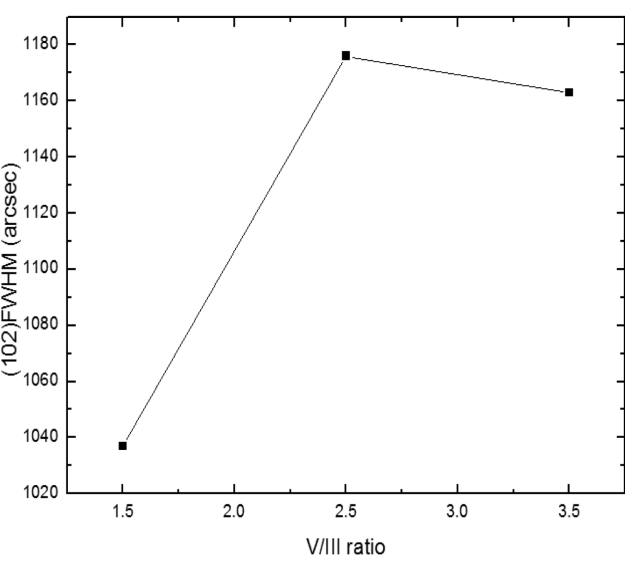

(b)

Fig. 5. FWHM of AlN epilayers with the variation of the V/III ratio (a) (002), (b) (102).

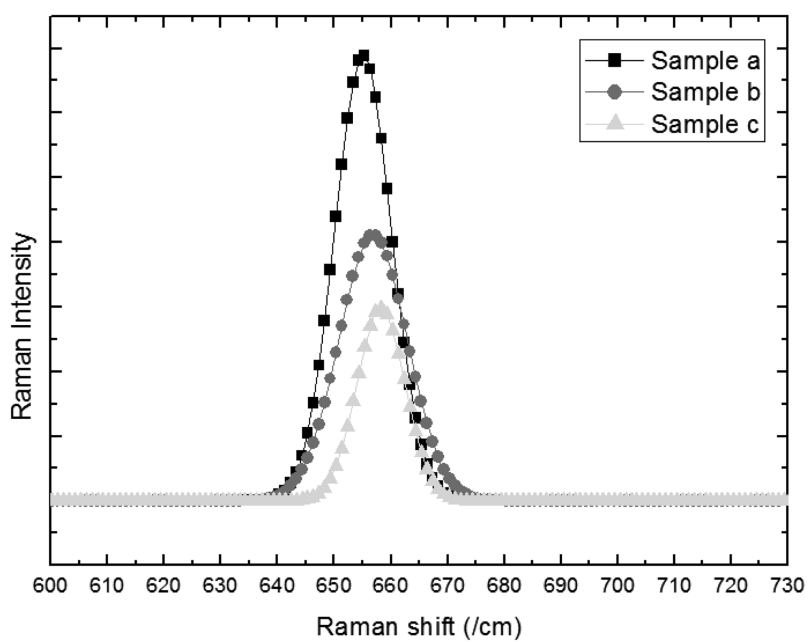

Fig. 6. Raman shift of AIN epilayers at different V/III ratio (a)1.5, (b) 2.5 and (c) 3.5 .

을 조사할 수 있고 (102) 비 대칭면은 $\mathrm{c}$ 축과 $\mathrm{a}$ 축의 모 든 threading dislocation을 측정할 수 있다. 그러므로 일 반적으로 (102) 비 대칭면이 더 큰 FWHM을 가진다. ${ }^{11,12)}$

(002) 대칭면의 $\mathrm{FWHM}$ 값은 $\mathrm{V} / \mathrm{III}$ 족 비가 $1.5,2.5$, 3.5 로 증가되면서 각각 $473 \mathrm{arcsec}, 484 \mathrm{arcsec}, 495 \mathrm{arcsec}$ 로 증가하였다. 이는 $\mathrm{V} / \mathrm{III}$ 족 비 증가에 따라 2 차원 성 장보다는 3 차원 성장을 한 결과 나선형 전위밀도가 증 가하고 막 품질이 나빠진 것으로 볼 수 있다. 한편 (102) 비 대칭면의 $\mathrm{FWHM}$ 값은 $\mathrm{V} / \mathrm{III}$ 족 비가 $1.5,2.5,3.5$ 로 증가하면서 $1037 \mathrm{arcsec}, 1176 \mathrm{arcsec}, 1163 \mathrm{arcsec}$ 로 V/III 족 비가 2.5 일 때까지 증가하다가 약간 감소하였다. 이 는 (102) 비대칭면도 $(002)$ 대칭면과 같이 $\mathrm{V} / \mathrm{III}$ 족 비 증 가에 따라 2 차원 성장보다는 3 차원 성장을 한 결과 threading dislocation이 증가하였기 때문으로 볼 수 있다. V/ III족 비가 3.5에서 (102) 비 대칭면의 결정성이 좋아지 는 현상에 대한 원인은 추가적으로 분석이 요구된다. Fig.
6은 사파이어 기판 위에 성장된 AIN 에피층의 Raman $\mathrm{E}_{2}$ high peak 값을 보여준다. 스트레스가 없는 상태에서 의 $\mathrm{AlN}$ 에피층의 $\mathrm{E}_{2}$ high peak 값은 $655 \mathrm{~cm}^{-1}$ 로 알려 져 있다. ${ }^{13)} \mathrm{V} / \mathrm{III}$ 족 비 증가에 따라 $\mathrm{E}_{2}$ high peak의 값은 시료 a $655.08 \mathrm{~cm}^{-1}$, 시료 b $656.85 \mathrm{~cm}^{-1}$, 시료 c 657.95 $\mathrm{cm}^{-1}$ 로 점차 증가하였다. 일반적으로 사파이어 기판 위 에 성장하는 $\mathrm{AlN}$ 에피층은 성장온도에서는 격자상수의 차이에 의해 인장응력 상태를 보이지만 상온에서는 열팽 창계수 차이에 의해 압축응력 상태를 보인다. ${ }^{8}$ 본 실험 결과에서도 $\mathrm{V} / \mathrm{III}$ 족 비 증가에 따라 성장된 $\mathrm{AIN}$ 에피층 의 Raman shift 값은 각각 $0.08,1.85,2.95$ 로 phonon mode가 장파장으로 이동되어, 에피층의 잔류응력은 모두 압축응력을 보이며 그 값은 점차 증가하는 것을 볼 수 있었다. 잔류 biaxial stress는 다음 식을 이용하여 구할 수 있다.

\section{$\Delta \omega \gamma=\mathrm{K} \gamma \sigma \mathrm{xx}$}

여기서 스트레스 계수 $\mathrm{K}$ 은 최근 Gleize et al의 연구 결과에서 $\mathrm{AIN}$ 에피층의 $\mathrm{E}_{2}$ high mode 일 때 $3.39 \mathrm{~cm}^{-1} /$ $\mathrm{GPa}$ 라고 알려져 있다. ${ }^{13)}$ 따라서 구해진 biaxial stress는 Raman shift가 증가함에 따라 $0.02 \mathrm{GPa}, 0.54 \mathrm{GPa}, 0.87$ $\mathrm{GPa}$ 로 증가한다. 결국 $\mathrm{V} / \mathrm{III}$ 족 비가 1.5 일 경우가 가장 스트레스가 없는 상태를 보였다. 한편 $\mathrm{V} / \mathrm{III}$ 족 비가 증가 하면 Raman peak의 강도도 감소하는 경향을 보였다. 결 정질은 $\mathrm{E}_{2}$ high peak의 상대적인 강도의 따라서도 측정 될 수 있다. ${ }^{14)} \mathrm{Fig} .5$ 의 X-ray rocking 결과에 보인 바와 같이 $\mathrm{V} / \mathrm{III}$ 족 비 증가에 따라 결정성이 나빠짐에 따라 Raman peak의 강도도 감소한 것으로 보인다.

\section{4. 결 론}

HVPE 장비를 이용하여 V/III족 비를 변화시켜서 AIN 
에피층을 성장하였다. $\mathrm{V} / \mathrm{III}$ 족 비는 $1.5,2.5,3.5$ 로 증가 됨에 따라 RMS roughness 값은 각각 $5.13 \mathrm{~nm}, 6.22$ $\mathrm{nm}, 6.86 \mathrm{~nm}$ 로 증가되어 표면조도가 나빠지는 것을 확 인하였다. 성장률도 $2.58 \mu \mathrm{m} / \mathrm{h}, 1.35 \mu \mathrm{m} / \mathrm{h}, 0.56 \mu \mathrm{m} / \mathrm{h}$ 로 줄어드는 것을 볼 수 있었다. 한편 $\mathrm{V} / \mathrm{III}$ 족 비가 증가함 에 따라 X-ray rocking 곡선의 FWHM은 대칭면 (002)에 서 $473 \mathrm{arcsec}, 484 \mathrm{arcsec}, 495 \mathrm{arcsec}$, 비대칭면 (102) 에서 $1037 \mathrm{arcsec}, 1176 \mathrm{arcsec}, 1163 \mathrm{arcsec}$ 로 변화되어 나타나 결정성이 떨어지는 것으로 나타났다. Raman 분석 결과에서도 $\mathrm{V} / \mathrm{III}$ 족 비가 1.5 일 때 $\mathrm{AIN}$ 에피층이 가장 스 트레스 없는 상태를 보이며 V/III족 비가 증가할수록 Raman peak의 강도도 감소하는 경향을 보여 결정성이 나빠지는 것을 확인할 수 있었다. V/III족 비가 증가하 면서 표면이 거칠어지고, 성장률이 낮아지고, 결정성이 떨 어지는 것으로 볼 때 $\mathrm{HVPE}$ 법에 의해 성장된 $\mathrm{AlN}$ 막의 품질은 본 실험 범위 내에서는 $\mathrm{V} / \mathrm{III}$ 족 비가 낮을수록 좋 아졌으며, 1.5 일 때 가장 표면상태가 좋고 스트레스가 없는 결정성이 좋은 에피층을 얻을 수 있었다.

\section{감사의 글}

본 연구는 지식경제부의 전략핵심소재 기술개발사업의 지원으로 이루어졌으며 이에 감사 드립니다(과제번호: 10043791).

\section{References}

1. M. Balaji, A. Claudel, V. Fellmann, I. Gelard, E. Blanquet, R. Boichot, A. Pierret B. Attal-Tretout, A. Crisci, S. Coindeau, H. Roussel, D. Pique, K. Baskar and M. Pons, J. Alloy. Comp., 526, 103 (2012).

2. Kohei Fujita, Kazuteru Okuura, Hideto Miyake, Kazumasa Hiramatsu, and Hideki Hirayama, Phys. Status
Solidi C, 8(5), 1483 (2011).

3. Yuta Takagi, Reina Miyagawa, Hideto Miyake and Kazumasa Hiramatsu, Phys. Status Solidi C, 9(3-4), 576 (2012).

4. Toru Nagashima, Manabu Harada, Hiroyuki Yanagi, Hiroyuki Fukuyama, Yoshinao Kumagai, Akinori Koukitu and Kazuya Takada, J. Cryst. Growth, 305, 355 (2007).

5. Yoshinao Kumagai, YuukiEnatsu, MasanariIshizuki, YukiKubota, JumpeiTajima, Toru Nagashima, HisashiMurakami, KazuyaTakada and AkinoriKoukitu, J. Cryst. Growth, 312, 2530 (2010).

6. Yoshino Kumagai, Hiroshi Shikauchi, Jun Kikuchi, Takayoshi Yamane, Yoshihiro Kangawa and Akinori Koukitu, Proc. $21^{\text {st }}$ century COE Joint Workshop on Bulk Nitrides IPAP Conf. Series 4 pp.9-13 (2003)

7. S. Corekc-i, M.K.Ozturk, M.Cakmak, S.Ozc-elik and E.Ozbay, Mater. Sci. Semicond. Process Volume 15, Issue 1, pp 32-36, February (2012).

8. Masataka Imura, Kiyotaka Nakano, Naoki Fujimoto, Narihito Okada, Krishnan Balakrishnan, Motoaki Iwaya, Satoshi Kamiyama, Hiroshi Amano, Isamu Akasaki, Tadashi Noro, Takashi Takagi and Akira Bandoh, Jpn. J. Appl. Phys., 45(11), 8639 (2006).

9. Yu-Huai Liu, Tomoaki Tanabe, Hideto Miyake, Kazumasa Hiramatsu, Tomohiko Shibata, Mutsuhiro Tanaka and Toshihiko Masa, Jpn. J. Appl. Phys., 44(17), L505 (2005).

10. D. G. Zhao, J. J. Zhu, D. S. Jiang, Hui Yang, J. W. Liang, X. Y. Li and H. M. Gong, J. Cryst. Growth, 289, 72 (2006).

11. K. H. Chang, M. S. Kwon and S. I. Cho, J. Institute of Industrial Technology, 12, 123 (2004).

12. J. Bai, T.Wang, P. J. Parbrook, K. B. Lee and A. G. Cullis, J. Cryst. Growth, 282, 290 (2005).

13. D. G. Zhao, S. J. Xu, M. H. Xie and S. Y. Tong, Appl phys Lett., 83(4), 28 july (2003).

14. J. H. Yang, S. M. Kang, D. V. Dinh and D. H. Yoon, Thin Solid Films, 517, 5057 (2009). 